\title{
UTILIZING RESPONSE SURFACE METHODS DESIGNS FOR OPTIMIZATION OF TECHNOLOGICAL PARAMETERS ON THE VIBRATION AMPLITUDE OF CNC ROUTER SPINDLE
}

\author{
Nguyen Huu Loc ${ }^{1,2}$ and Nguyen Phuoc Hung ${ }^{1,2}$ \\ ${ }^{1}$ Faculty of Mechanical Engineering, Ho Chi Minh City University of Technology (HCMUT) \\ ${ }^{2}$ Vietnam National University of Ho Chi Minh city, Tel.: +84913603264, e-mail: nhloc@hcmut.edu.vn
}

Received Date: September 21, 2019; Revised Date: May 17, 2020; Acceptance Date: September 14, 2020

\begin{abstract}
For CNC machines, machining accuracy is of ultimate importance since it determines the quality of the products. Among many factors, vibration amplitude and stiffness are the key ones that influence the machining accuracy of a CNC machine. Remarkably, it is essential to conduct study into structural stiffness and the effect of technological parameters on the vibration amplitude of CNC router spindle with various second-order designs in order to improve machining accuracy. The research focuses on the application and comparison of the response-surface methods, the experimental research on the factors affecting the vibration amplitude, and the determination of the optimal working parameters for the $\mathrm{CNC}$ router.
\end{abstract}

Keywords: CNC router structure, Design of experiments, Stiffness, Vibration amplitude

\section{Introduction}

The quality and accuracy of the CNC router with a structure made of the welded structure, bolts, or castings, depend on the quality and accuracy of the machine structure components as well as the coupling and transmission drives in CNC router such as bolt joints, weld joints, sliding guidelines, and ball screws $[1,2]$. In the operation process, the joints break down the continuity of the machine structure, making the dynamic properties of the machine structure be affected by the machine components and the dynamic properties of the joints.

The welding method is often applied to make bed frame and column of a machine. The structure of the machine which uses structural (shaped) steel and is linked together by welding joint has the advantage of showing the ability to easily change its size and the capacity to be quickly designed or fabricated. However, the damping of the structure is a significant issue. Unlike cast iron, the welded structure of structural steel restricts internal damping and, therefore, is highly susceptible to unwanted vibration. Especially for highspeed CNC router structure, the spindle speed can reach up to $40000 \mathrm{rpm}$. In order to achieve such a spindle speed, it is necessary that the machine structure constantly ensure durability, rigidity, and good vibration resistance [3, 4].

$\mathrm{CNC}$ router structure design has suitable rigidity to reduce vibration and increase stability during machining [5]. Usually, the first natural frequency of rigging machine 
structure is rarely higher than $100 \mathrm{~Hz}$, corresponding to the spindle speed of about $6000 \mathrm{rpm}$ $[6,7]$. Machines with natural frequencies below $150 \mathrm{~Hz}$ cannot process high-quality products. Therefore, to have CNC machines for high-speed machining operations, it is necessary to design the machine structure to ensure stiffness and vibration stability.

Studies show that approximately $60 \%$ of total dynamic stiffness, and about $90 \%$ of the total damping of the machine structure comes from joints and drive components [8]. Hence, the study into the effects of different types of joints and transmission drives in general and couplings in particular on the dynamic characteristics of $\mathrm{CNC}$ machine structure is a considerable issue today. In the paper [8], three factors affecting router position accuracy are respectively stiffness of structure, control program accuracy, and control mechanisms accuracy. The author identified the error characteristics of three dimensions causing position errors and measured the vibration and vibration spectrum of the machine. Machine structure stiffness, which is associated with its displacement, is greatest when both $\mathrm{x}$ and $\mathrm{y}$ axes are consoles. Meanwhile, the vibration of the machine spindle depends on its positions. The author obtained the highest vibration level at the last (endpoint) position.

In this paper, the response surface method based on the three methods of quadratic experimental design was employed together with an analysis of variance and regression analysis. A comparison of the three different approaches was also carried out.

In addition, those factors affecting the vibration of $\mathrm{CNC}$ routers using welding joints and bolts were studied. The purpose was to improve the stiffness for machine structure, increase vibration resistance at high-speed operation and avoid resonance so as to achieve the best machining surface quality. At the same time, a potentially suitable approach of experimental planning for studying CNC router was offered and adopted. The study was conducted on a model of CNC router in the form of moving gantry, fixed tables.

\section{Response Surface with Second-Degree Polynomial}

A second-order (quadratic) model is typically used in response surface design of experiments; and depending on the output quantity for each factor, it is necessary that the form of parabolic equations be chosen. The second-degree polynomial model has the general form (Equation 1):

$$
y=b_{0}+\sum_{i=1}^{k} b_{i} x_{i}+\sum_{i=1}^{k} b_{i i} x_{i}^{2}+\sum_{\substack{i \neq j \\ i, j=1}}^{k} b_{i j} x_{i} x_{j}
$$

where: b0, bi,bij and bii are regression coefficients; xi, xj are the coded values of input factors.

According to the modern viewpoint in the response surface methodology, the experiment takes place from many different standards, associating with the evaluation of parameters of the regression model received. In the study, the researchers constructed a quadratic orthogonal experimental plan, thereby it was not compulsory to re-evaluate the independent regression coefficients. For these plans, the matrix $\left(\mathbf{X}^{\mathbf{T}} \mathbf{X}\right)^{-\mathbf{1}}$ is the diagonal matrix, so covariant between all regression coefficients is $0\left(\operatorname{cov}\left\{b_{i}, b_{j}\right\}=0\right.$ when $\left.i \neq j\right)$. However, the orthogonality of second-order planning is not related to the requirement to improve the accuracy of mathematical models, but only means to foster convenience in calculation. 
The quadratic design of experimental methods includes: Face - Centered Central Composite design (FCCCD) (Figure 1a), Box - Hunter (Rotatable Central Composite Design - RCCD) - figure 1b), Box - Wilson (Central Composite Orthogonal Design - CCOD). Additionally, there is 3k plan (Taguchi - Figure 1c), D optimal plan (Figure 1d, 1-13), and Box-Behnken (Figure 1d, 1-15). In this paper, the researchers compared the three methods: FCCCD, Box - Hunter, and Box-Behnken; and the design matrix is presented in Table 1.
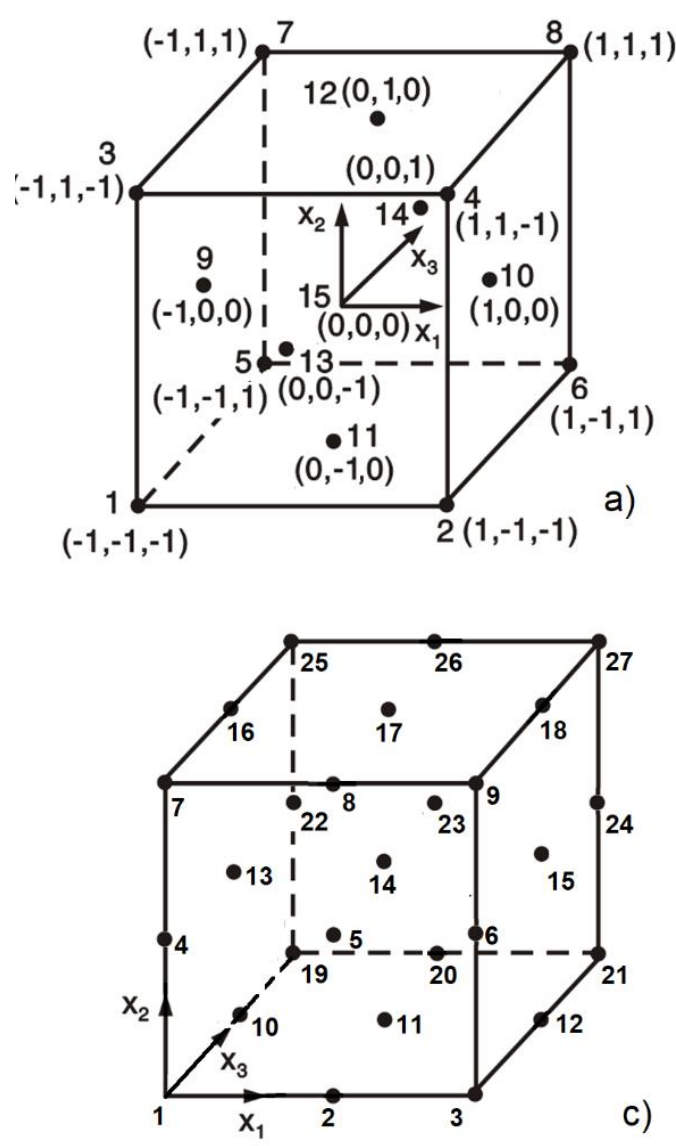

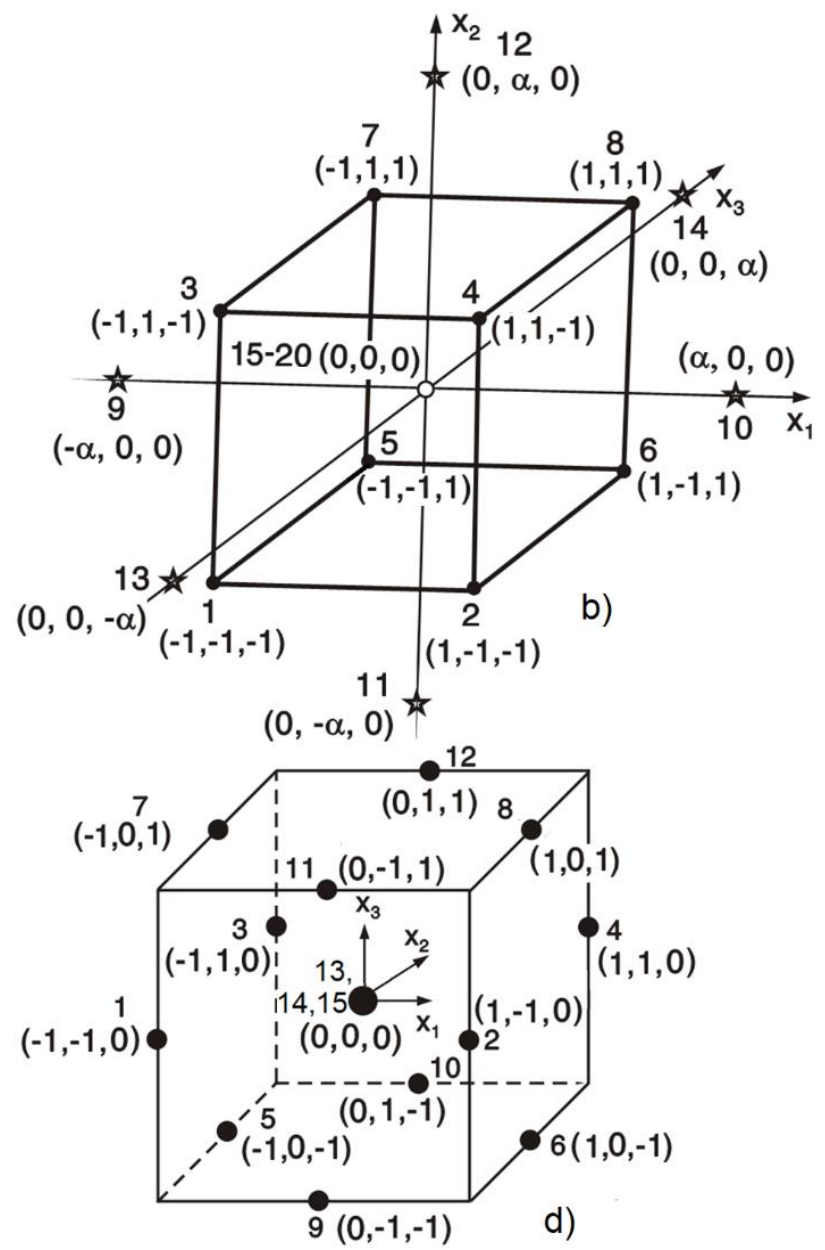

Figure 1. Location of experimental points for response surface design of experiments with three factors

Since all response-surface designs, including 3k, Box-Behnken, D-optimal, and Central Composite, deliver models with main effects, two-factor interactions, and quadratic terms, other criteria besides which model can be fitted must be considered in deciding which design should be used for a response surface experiment. There are three criteria employed to compare the design families, i.e. the number of observations in the design and the number of error degrees of freedom; the number of levels required for each design variable; and the safety of the highest and lowest variable levels.

As will be seen, these criteria are so essential that different designs tend to be preferred under different circumstances. While one criterion might be more important than the others for a particular design problem, all the three criteria must be considered and managed simultaneously. 
The accuracy of the mathematical model is determined by the variance of the regression equation coefficients and the experimental results. Thus, from the experimental point of view, the best planning is the one that allows obtaining a regression model with the smallest value of variance. The required numbers of experimental points for FCCCD, Box Hunter, and Box-Behnken are determined by using expression (Equation 2). In this paper, $\mathrm{k}$ $=3$, and the required numbers $\mathrm{N}$ of experimental points were determined as followings: $\mathrm{N}=$ 15 for FCCCD, $\mathrm{N}=20$ for Box - Hunter, and $\mathrm{N}=15$ for Box - Behnken (Table 1).

$$
\mathrm{N}=\left\{\begin{array}{l}
2^{\mathrm{k}}+2 \mathrm{k}+\mathrm{n}_{01} \text { for } \text { FCCCD plan } \\
2^{\mathrm{k}}+2 \mathrm{k}+\mathrm{n}_{02} \text { for Box }- \text { Hunter plan } \\
\mathrm{k} 2^{\mathrm{k}-1}+\mathrm{n}_{03} \quad \text { for Box }- \text { Behnken plan }
\end{array}\right.
$$

where: $\mathrm{k}$ is the number of parameters, $\mathrm{n}_{0 \mathrm{i}}$ is the repeated design number on the average level, $2 \mathrm{k}$ is the design number on central axes. Coordinate $\alpha$ is determined by expression $\alpha=\left(2^{\mathrm{k}}\right)^{1 / 2}$

Table 1. The Design Matrix for Box-Hunter, FCCCD and Box-Behnken with Three Factors

\begin{tabular}{|c|c|c|c|c|c|c|c|c|c|c|c|c|c|}
\hline \multirow[b]{2}{*}{$\mathrm{N}^{\mathrm{o}}$} & \multicolumn{4}{|c|}{$\begin{array}{l}\text { Box-Hunter } \\
\text { (Figure 1b) }\end{array}$} & \multicolumn{4}{|c|}{$\begin{array}{c}\text { FCCCD } \\
\text { (Figure 1a) }\end{array}$} & \multicolumn{4}{|c|}{$\begin{array}{c}\text { Box-Behnken } \\
\text { (Figure 1d) }\end{array}$} & \multirow[t]{2}{*}{$\begin{array}{l}\text { Results } \\
\qquad Y_{i}\end{array}$} \\
\hline & No. & $\mathbf{X}_{1}$ & $\mathbf{x}_{2}$ & $\mathbf{X} 3$ & No. & $\mathbf{x}_{1}$ & $\mathbf{x}_{2}$ & $\mathbf{X}_{3}$ & No. & $\mathbf{x}_{1}$ & $\mathbf{X}_{2}$ & $\mathbf{x}_{3}$ & \\
\hline 1 & 1 & -1 & -1 & -1 & 1 & -1 & -1 & -1 & 1 & -1 & -1 & 0 & $\mathrm{Y}_{1}$ \\
\hline 2 & 1 & +1 & -1 & -1 & 1 & +1 & -1 & -1 & 1 & +1 & -1 & 0 & $\mathrm{Y}_{2}$ \\
\hline 3 & 1 & -1 & +1 & -1 & 1 & -1 & +1 & -1 & 1 & -1 & +1 & 0 & $\mathrm{Y}_{3}$ \\
\hline 4 & 1 & +1 & +1 & -1 & 1 & +1 & +1 & -1 & 1 & +1 & +1 & 0 & $Y_{4}$ \\
\hline 5 & 1 & -1 & -1 & +1 & 1 & -1 & -1 & +1 & 1 & -1 & 0 & -1 & $\mathrm{Y}_{5}$ \\
\hline 6 & 1 & +1 & -1 & +1 & 1 & +1 & -1 & +1 & 1 & +1 & 0 & -1 & . \\
\hline 7 & 1 & -1 & +1 & +1 & 1 & -1 & +1 & +1 & 1 & -1 & 0 & +1 & . \\
\hline 8 & 1 & +1 & +1 & +1 & 1 & +1 & +1 & +1 & 1 & +1 & 0 & +1 & . \\
\hline 9 & 1 & -1.682 & 0 & 0 & 1 & -1 & 0 & 0 & 1 & 0 & -1 & -1 & . \\
\hline 10 & 1 & 1.682 & 0 & 0 & 1 & +1 & 0 & 0 & 1 & 0 & +1 & -1 & . \\
\hline 11 & 1 & 0 & -1.682 & 0 & 1 & 0 & -1 & 0 & 1 & 0 & -1 & +1 & . \\
\hline 12 & 1 & 0 & 1.682 & 0 & 1 & 0 & +1 & 0 & 1 & 0 & +1 & +1 & . \\
\hline 13 & 1 & 0 & 0 & -1.682 & 1 & 0 & 0 & -1 & 1 & 0 & 0 & 0 & . \\
\hline 14 & 1 & 0 & 0 & 1.682 & 1 & 0 & 0 & +1 & 1 & 0 & 0 & 0 & . \\
\hline $15-20$ & 6 & 0 & 0 & 0 & 1 & 0 & 0 & 0 & 1 & 0 & 0 & 0 & $\mathrm{Y}_{\mathrm{N}}$ \\
\hline
\end{tabular}

The regression coefficients were defined by the least squares estimate by Equation 3, and $\mathrm{B}$ is a $q \times 1$ matrix, where $q$ is number of the regression coefficients. $X$ is a $N \times q$ matrix of constants determined by the design and other structures of the system (Equation 4), $\mathrm{X}^{\mathrm{T}}$ is a $\mathrm{q} \times \mathrm{N}$ matrix - the transposition matrix of $\mathrm{X} . \mathrm{Y}$ is a $\mathrm{N} \times 1$ vector of random variables representing responses to be observed, one per experimental unit.

$$
\mathrm{B}=\left(\mathrm{X}^{\mathrm{T}} \mathrm{X}\right)^{-1}\left(\mathrm{X}^{\mathrm{T}} \mathrm{Y}\right)
$$




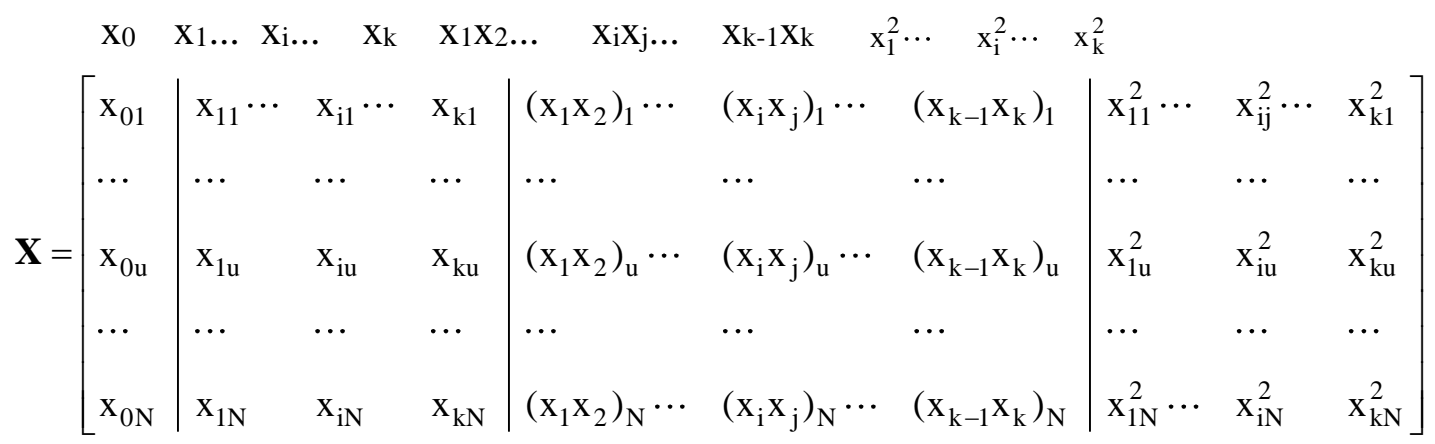

After the calculation of those coefficient values in the regression equation, it was necessary to test their significance and eliminate the insignificant individual regression coefficients. In the Significance test table, the P-value of less than 0.05 indicated that the model terms could be considered significant. For testing lack of fit in regression, to perform the analysis of variance for Significance of regression, an analysis of variance and regression analysis were performed with the use of Minitab software (version16.0).

\section{Results and Discussion}

\section{Experimental Models and Measuring Instruments}

Experiments were performed on a CNC router using welded structures, as shown in Figure $2 \mathrm{a}$. The lowest natural frequency of this machine was $250 \mathrm{~Hz}$. The equipment utilized to check the spindle vibration of the $\mathrm{CNC}$ router included the PCB 603C01 acceleration sensor, PCB group, and acceleration sensitivity $10.2 \mathrm{mV} / \mathrm{g}$. The accelerometer detected the multichannel NI SCXI-1000DC meter used for vibration analysis. To properly operate the NI SCXI-1000DC system, NI Signal Express software was employed to display the results of vibration data on personal computer.

Experimental measuring devices are shown in Figure 2b, c. The accelerometer sensor was attached to the main axis of the machine while the NI SCXI -1000DC measuring device was connected to the accelerometer and the computer. Measurement data were collected and displayed via NI Signal Express software. Besides, LabView software was also utilized to easily display measurement results, store, and process data.

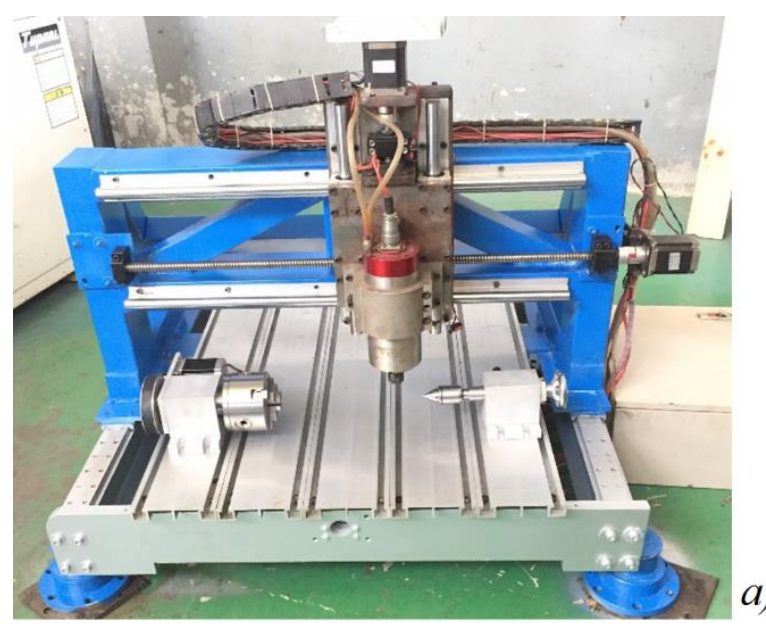

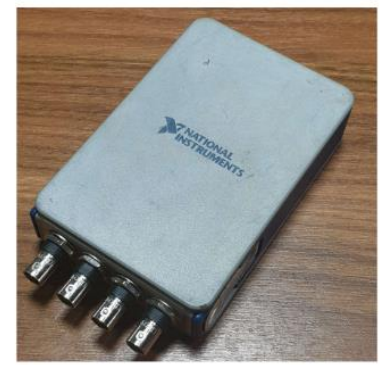

b)

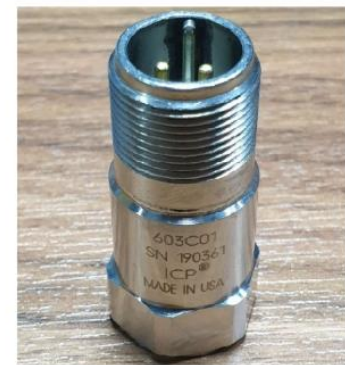

c)

Figure 2. Model and measuring devices used in the experiment; (a) Experimental model; (b) Multi-channel NI SCXI-1000DC device; (c) PCB 603C01 accelerometer sensor 


\section{Experiments and Results}

Many factors affect the spindle vibration amplitude; however, through the process of studying the relevant researches, selected machining parameters were spindle speed, tool speed, and cutting depth [10]. Cutting parameters were considered as inputs while spindle vibration was regarded as output parameters in the experimental process. The theory of design of experiments and mathematical-statistical analysis use coded values of input factors of milling process. The coded values of the three independent input factors obtained value of: five levels for Box-Hunter from -1.682, -1, 0, 1, +1.682 and three levels for FCCCD and Box-Behnken from -1, 0 1. The technological parameters of each factor found in this research are shown in Table 2. The number of replicates $n$ (replication) for each method was: Box-Hunter and Box-Behnken: $\mathrm{n}=7$; FCCCD: $\mathrm{n}=$ 8. Minitab software was utilized to calculate the value of the coefficients in the regression equation of coefficients in coded and natural form, and the results are shown in Table 3.

Table 2. Levels of Machining Parameters

\begin{tabular}{|c|c|c|c|c|c|c|c|}
\hline \multirow[b]{2}{*}{ Factors } & \multicolumn{2}{|c|}{ Factor Symbol } & \multicolumn{5}{|c|}{ Levels of Cutting Parameters } \\
\hline & $\begin{array}{l}\text { Actual } \\
\text { Factor }\end{array}$ & $\begin{array}{l}\text { Coded } \\
\text { Factor }\end{array}$ & $\begin{array}{r}\text { Level } \\
-1.682 \\
\end{array}$ & $\begin{array}{c}\text { Level } \\
-1 \\
\end{array}$ & $\begin{array}{c}\text { Level } \\
0\end{array}$ & $\begin{array}{c}\text { Level } \\
1 \\
\end{array}$ & $\begin{array}{c}\text { Level } \\
+-1.682 \\
\end{array}$ \\
\hline Spindle speed, rpm & $\mathrm{n}$ & $\mathrm{X}_{1}$ & 5000 & 8400 & 10000 & 13400 & 15000 \\
\hline Cutting depth, mm & $\mathrm{t}$ & $\mathrm{x}_{2}$ & 0.7 & 1.1 & 1.3 & 1.7 & 1.9 \\
\hline $\begin{array}{l}\text { The feeding speed, } \\
\mathrm{mm} / \mathrm{min}\end{array}$ & S & $\mathrm{X}_{3}$ & 500 & 800 & 1000 & 1300 & 1500 \\
\hline
\end{tabular}

Table 3. Summary Table of Coefficients

\begin{tabular}{|c|c|c|c|c|c|c|}
\hline \multirow[b]{2}{*}{ Coefficients } & \multicolumn{3}{|c|}{ Coded Form } & \multicolumn{3}{|c|}{ Natural Form } \\
\hline & $\begin{array}{l}\text { Box - } \\
\text { Hunter }\end{array}$ & FCCCD & $\begin{array}{l}\text { Box- } \\
\text { Behnken }\end{array}$ & $\begin{array}{l}\text { Box - } \\
\text { Hunter }\end{array}$ & FCCCD & $\begin{array}{l}\text { Box- } \\
\text { Behnken }\end{array}$ \\
\hline $\mathrm{b}_{0}$ & 153.697 & 213.907 & 153.029 & 830.1 & 1699 & 5825 \\
\hline $\mathrm{b}_{1}$ & -272.432 & -175.509 & -147.839 & -0.10091 & -0.7124 & -0.2201 \\
\hline $\mathrm{b}_{2}$ & 75.012 & 46.514 & 5.186 & 2241 & 2241 & -2954 \\
\hline $\mathrm{b}_{3}$ & 15.518 & 8.174 & 6.521 & 2.068 & 2.068 & -4.015 \\
\hline$b_{11}$ & 284.923 & 200.413 & 61.743 & 0.000032 & 2.068 & 0.000010 \\
\hline$b_{22}$ & 45.816 & -61.674 & 60.729 & -685 & -685 & 674.8 \\
\hline$b_{33}$ & 12.402 & -73.787 & 57.564 & 0.000018 & -0.001181 & 0.000921 \\
\hline$b_{12}$ & -89.217 & -32.419 & -31.729 & -0.01051 & -0.04322 & -0.04230 \\
\hline$b_{13}$ & 11.294 & 2.181 & 2.864 & 0.000002 & 0.000003 & 0.000005 \\
\hline$b_{23}$ & 59.862 & 21.725 & 110.214 & 0.0705 & 0.2897 & 1.4695 \\
\hline
\end{tabular}

Due to testing lack of fit in regression, the analysis of variance for significance of regression was performed, and the regression model fit well. Next, the researchers calculated the $\mathrm{Y}^{*}$ value of the regression equation, and checked the variance between the obtained results and the experimental data, Table 5 describes these operations. The researchers found that the R-square of the Box-Hunter method was significantly smaller than the other two methods, so this experimental method was eminently suitable for describing the vibration 
characteristics of the $\mathrm{CNC}$ router (Table 4). Following the assessment of the individual regression coefficients testing and the appropriateness according to the statistical hypotheses (Table 6), the coefficient $b_{13}$ (ns) must be eliminated because it was insignificant ( $T$ Value $=1.18$ ). The actual form of final regression equation is presented in Equation 5 .

$Y=814.1-0.09932 n-8.1 t-0.1083 s+0.000004 n^{2}+45.00 t^{2}+0.000018 s^{2}-0.01051 n t$ +0.0705 ts

Table 4. Model summary

\begin{tabular}{lllll}
\multicolumn{1}{c}{ Plan } & S & R-sq & R-sq(adj) & R-sq(pred) \\
\hline Box- Hunter & 25.2857 & $97.87 \%$ & $97.72 \%$ & $97.43 \%$ \\
FCCCD & 53.9724 & $91.71 \%$ & $91.11 \%$ & $90.39 \%$ \\
Box - Behnken & 34.8905 & $94.08 \%$ & $93.52 \%$ & $92.59 \%$
\end{tabular}

Table 5. Correlation between Experimental $Y$ and Calculated Results $Y^{*}$

\begin{tabular}{|c|c|c|c|c|c|c|c|c|c|}
\hline \multirow{2}{*}{$\mathbf{N}^{0}$} & \multicolumn{3}{|c|}{ Box - Hunter } & \multicolumn{2}{|c|}{ FCCCD } & \multicolumn{4}{|c|}{ Box-Behnken } \\
\hline & $\mathbf{Y}$ & $\mathbf{Y}^{*}$ & Resid & $\mathbf{Y}$ & $\mathbf{Y}^{*}$ & Resid & $\mathbf{Y}$ & $\mathbf{Y}^{*}$ & Resid \\
\hline 1 & 380.77 & 376.789 & 19.9037 & 384.95 & 391.168 & -5.268 & 348.7 & 386.425 & -37.7250 \\
\hline 2 & 96.47 & 107.911 & -2.0041 & 95.88 & 100.625 & 12.275 & 115.8 & 154.204 & -38.4036 \\
\hline 3 & 450.51 & 486.751 & -34.8585 & 451.46 & 505.583 & -42.483 & 504.9 & 460.254 & 44.6464 \\
\hline 4 & 137.54 & 91.702 & 50.6052 & 137.03 & 85.365 & 64.335 & 148.2 & 101.118 & 47.0821 \\
\hline 5 & 295.75 & 344.929 & -58.6220 & 300.45 & 359.703 & -64.903 & 404.0 & 416.518 & -12.5179 \\
\hline 6 & 124.94 & 92.023 & 47.1701 & 124.40 & 77.885 & 30.215 & 112.4 & 115.111 & -2.7107 \\
\hline 7 & 547.64 & 539.548 & 2.9587 & 558.16 & 561.018 & 4.582 & 424.1 & 423.832 & 0.2679 \\
\hline 8 & 153.11 & 160.471 & 4.4223 & 148.12 & 149.525 & -5.025 & 132.4 & 133.882 & -1.4821 \\
\hline 9 & 753.04 & 711.052 & 38.0480 & 712.25 & 589.829 & 117.471 & 428.9 & 369.829 & 59.0714 \\
\hline 10 & 128.95 & 166.188 & -37.5883 & 146.82 & 238.811 & -97.411 & 116.6 & 159.771 & -43.1714 \\
\hline 11 & 137.01 & 124.501 & 17.6992 & 129.41 & 105.719 & 33.781 & 211.7 & 162.443 & 49.2571 \\
\hline 12 & 266.80 & 274.525 & -16.2251 & 205.44 & 198.746 & 2.754 & 351.5 & 393.243 & -41.7429 \\
\hline 13 & 147.71 & 150.581 & 0.0195 & 145.35 & 131.946 & 18.854 & 152.7 & 153.029 & -0.3286 \\
\hline 14 & 189.22 & 181.617 & 5.6831 & 165.31 & 148.294 & 19.506 & 153.5 & 153.029 & 0.4714 \\
\hline 15 & 151.06 & 153.697 & -9.7972 & 156.5 & 213.907 & -61.207 & 150.8 & 153.029 & -2.2286 \\
\hline 16 & 161.41 & 153.697 & 15.7028 & & & & & & \\
\hline 17 & 149.79 & 153.697 & 2.8028 & & & & & & \\
\hline 18 & 152.57 & 153.697 & -0.9972 & & & & & & \\
\hline 19 & 155.78 & 153.697 & -0.1972 & & & & & & \\
\hline 20 & 150.70 & 153.697 & -2.8972 & & & & & & \\
\hline
\end{tabular}


Table 6. Coded Coefficients Testing

\begin{tabular}{crrrrr} 
Term & Coef & SECoef & T-Value & P-Value & VIF \\
\hline Constant & 153.70 & 3.90 & 39.37 & 0.000 & \\
$\mathrm{n}$ & -161.99 & 2.59 & -62.54 & 0.000 & 1.00 \\
$\mathrm{t}$ & 44.60 & 2.59 & 17.22 & 0.000 & 1.00 \\
$\mathrm{~s}$ & 9.23 & 2.59 & 3.56 & 0.001 & 1.00 \\
$\mathrm{n}^{2}$ & 100.74 & 2.52 & 39.95 & 0.000 & 1.02 \\
$\mathrm{t}^{2}$ & 16.20 & 2.52 & 6.42 & 0.000 & 1.02 \\
$\mathrm{~s}^{2}$ & 4.38 & 2.52 & 1.74 & 0.084 & 1.02 \\
$\mathrm{nt}$ & -31.54 & 3.38 & -9.32 & 0.000 & 1.00 \\
$\mathrm{ts}$ & 21.16 & 3.38 & 6.25 & 0.000 & 1.00 \\
\hline
\end{tabular}

\section{Evaluation of Experimental Results}

During the milling process, machining parameters, including the cutting speed, cutting depth, and selected feeding speed, were the factors needed for the study into spindle vibration impact. The effect of machining parameters on vibration amplitude was analyzed, based on the mathematical model obtained.

From the results according to Equation (5), Graph 3, 4 and 5 were constructed within the empirical values. The diagrams in Figure 3, 4 and 5 show the relationship of the three factors affecting the spindle vibration amplitude of the CNC router. It could be seen that the trend of the spindle's vibration amplitude decreased slightly as the cutting speed increased as it promoted the rotation stability of the spindle head, leading to the elimination of the vibration amplitude. Tool runs also tended to be similar to cutting speeds; however, the cutting depth factor had the opposite effect, i.e. when the cutting depth rose, the vibration amplitude of the spindle would increase accordingly.
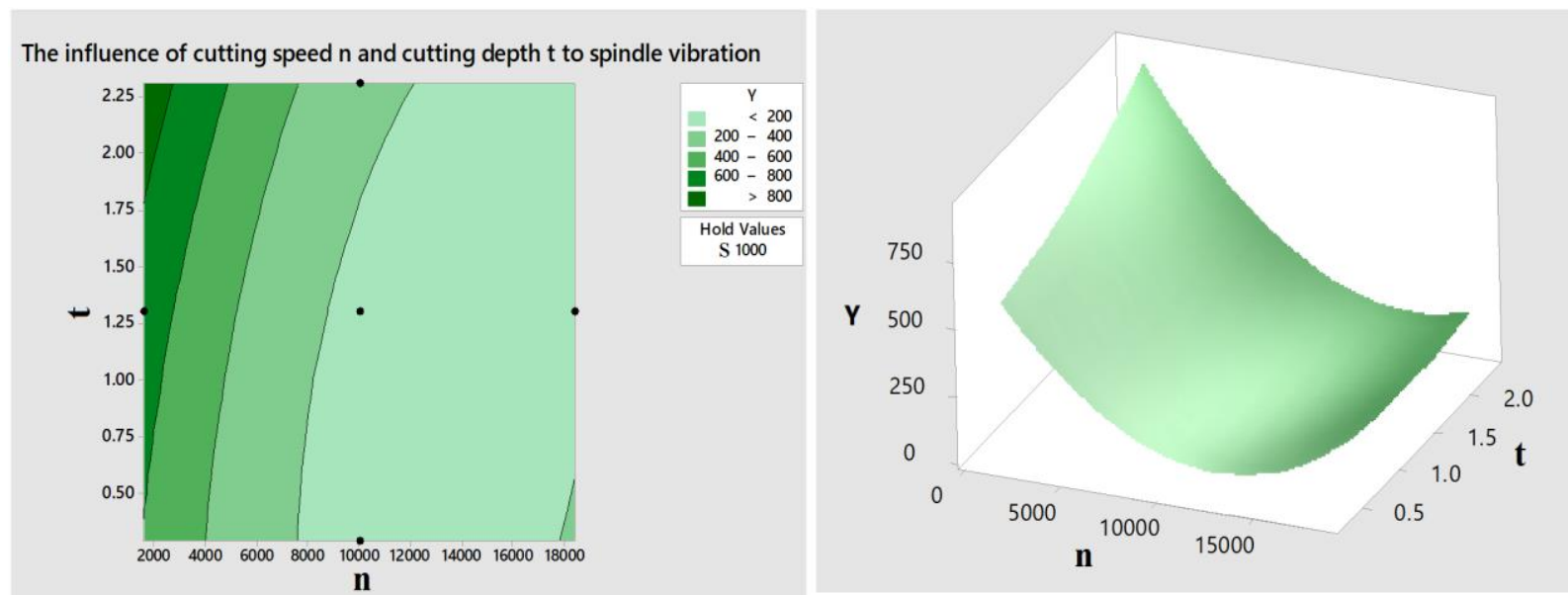

Figure 3. The graph shows the influence of cutting speed $n$ and cutting depth $t$ on spindle vibration $\mathrm{Y}$ 

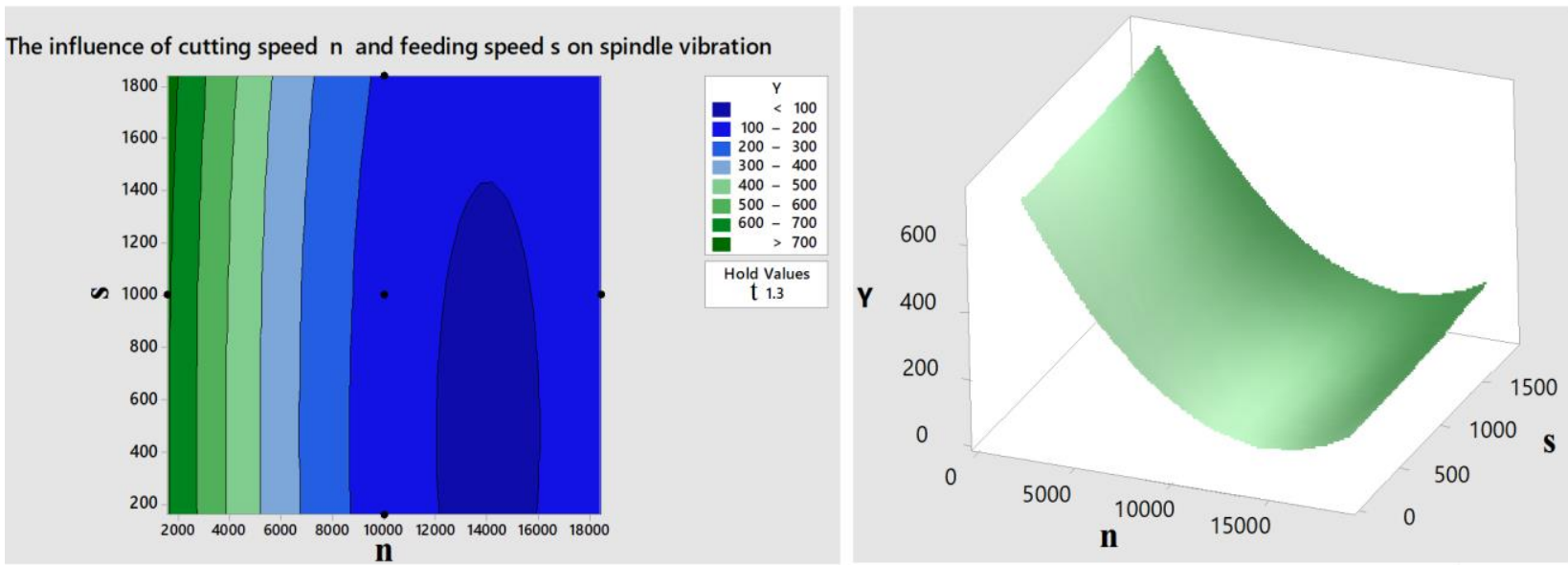

Figure 4. The graph shows the influence of cutting speed $\mathrm{n}$ and feeding speed $\mathrm{s}$ on spindle vibration $\mathrm{Y}$
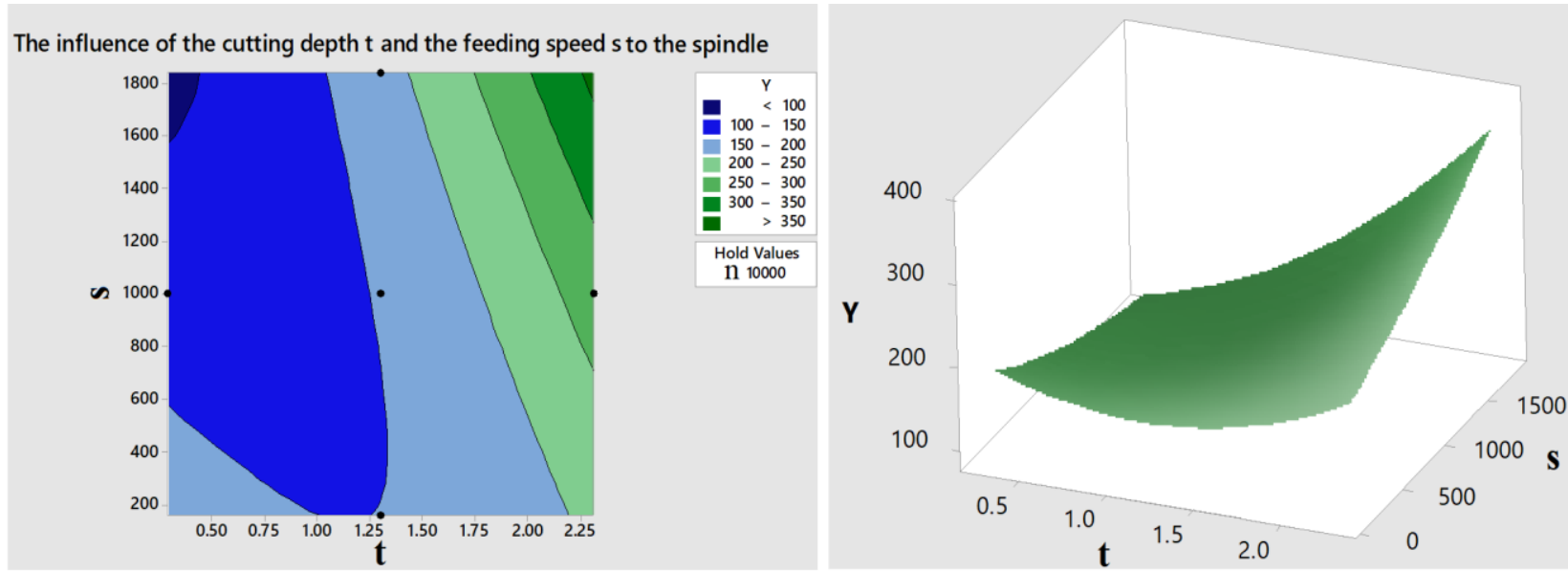

Figure 5. The graph shows the influence of the cutting depth $t$ and the feeding speed s on the spindle vibration $\mathrm{Y}$

The Response optimizer of Minitab was used to find the optimal working parameters. The selected milling machine model had the smallest vibration amplitude of $75.5189 \mu \mathrm{m}$ when working with $13282.8 \mathrm{rpm}$ cutting speed, cutting depth of $0.7 \mathrm{~mm}$ and feeding speed of $1500 \mathrm{~mm} / \mathrm{min}$ (Figure 6).

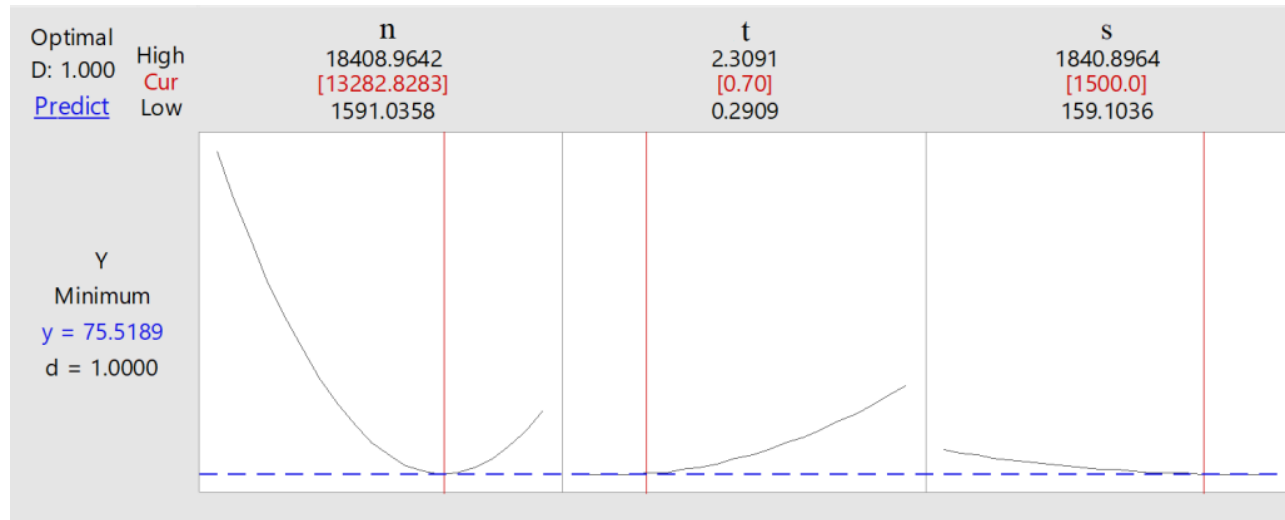

Figure 6. Response optimizer: The smallest vibration amplitude of $75.5189 \mu \mathrm{m}$ 


\section{Conclusions}

The paper presented the response surface design of experiments. The experimental process demonstrated the effect of three cutting parameters on the spindle vibration amplitude of the $\mathrm{CNC}$ router using welding structure and selecting experimental planning fit. With regard to CNC router structure, the welding method can be fully used to join the components in the machine frame instead of the traditional method of using bolts when it is necessary to increase the stiffness of the machine as well as improve the machine accuracy.

The Box-Hunter design is the best method that describes the vibration characteristics of the spindle under the influence of the three cutting parameters, including spindle speed, feeding speed, and cutting depth. Nevertheless, from an experimental point of view, Box-Behnken and FCCCD are very beneficial owing to the fact that the factors are varied at three levels instead of five levels for Box - Hunter and the implementation of Box - Hunter is quite laborious due to the large number of experiments.

When spindle speed and feeding speed are increased, vibration measurements tend to decrease. The working parameters of $\mathrm{CNC}$ router reach optimal state at cutting speed of $13282.8 \mathrm{rpm}$, cutting depth of $0.7 \mathrm{~mm}$, and feeding speed of $1500 \mathrm{~mm} / \mathrm{min}$.

\section{Acknowledgement}

This research is supported by Vietnam National University - Ho Chi Minh City (VNUHCM).

\section{References}

[1] Y. Liang, W. Chen, Q. Bai, Y. Sun, G. Chen, Q. Zhang, and Y. Sun, "Design and dynamic optimization of an ultraprecision diamond flycutting machine tool for large KDP crystal machining," The International Journal of Advanced Manufacturing Technology, Vol. 69, pp. 237-244, 2013.

[2] S.W. Lee, R. Mayor, and J. Ni, "Dynamic analysis of a mesoscale machine tool," Journal of Manufacturing Science and Engineering, Vol. 128, pp. 194-203, 2006.

[3] D. Biermann, and A. Baschin, "Influence of cutting edge geometry and cutting edge radius on the stability of micromilling processes," Production Engineering, Vol. 3, pp. 375-380, 2009.

[4] H. Du, and C. Zhao, "Stability criteria based on argument principle of a general dynamical system in cutting process," The International Journal of Advanced Manufacturing Technology, Vol. 70, pp. 747-753, 2014.

[5] J.D. Suh, "Design and manufacture of hybrid polymer concrete bed for high-speed CNC router," International Journal of Mechanics and Materials in Design, Vol. 4, pp. 113-121, 2008.

[6] K. Fansen, and Y. Junyi, "Fuzzy dynamic response analysis of machine tool structure," International Journal of Machine Tools and Manufacture, Vol. 39, No. 12, pp. 1993 2002, 1999.

[7] P. Albertelli, N. Cau, G. Bianchi, and M. Monno, "The effects of dynamic interaction between machine tool subsystems on cutting process stability," The International Journal of Advanced Manufacturing Technology, Vol. 58, pp. 923-932, 2012. 
[8] G. Zhang, Y. Huang, W. Shi, and W. Fu, "Predicting dynamic behaviours of a whole machine tool structure based on computer-aided engineering," International Journal of Machine Tools and Manufacture, Vol. 43, pp. 699-706, 2003.

[9] N.H. Loc, Design and Analysis of Experiments, National University Publisher HCMC, Ho Chi Minh city, Vietnam, 2014.

[10] T.V. Thuy, and N.H. Loc, "Investigation on influence of cutting parameters on spindle vibration of CNC wood milling machine," In: O.S. Es-Said ed., The 6th Asia Conference on Mechanical and Materials Engineering, Trans Tech Publications Ltd., Seoul, South Korea, p. 01007, 2018. 